This item was submitted to Loughborough's Research Repository by the author.

Items in Figshare are protected by copyright, with all rights reserved, unless otherwise indicated.

\title{
Driver sleepiness on YouTube: A content analysis
}

\section{PLEASE CITE THE PUBLISHED VERSION}

http://dx.doi.org/10.1016/j.aap.2015.11.025

\section{PUBLISHER}

(c) Elsevier

\section{VERSION}

AM (Accepted Manuscript)

\section{PUBLISHER STATEMENT}

This work is made available according to the conditions of the Creative Commons Attribution-NonCommercialNoDerivatives 4.0 International (CC BY-NC-ND 4.0) licence. Full details of this licence are available at: https://creativecommons.org/licenses/by-nc-nd/4.0/

\section{LICENCE}

CC BY-NC-ND 4.0

\section{REPOSITORY RECORD}

Hawkins, A.N., and Ashleigh J. Filtness. 2019. "Driver Sleepiness on Youtube: A Content Analysis". figshare. https://hdl.handle.net/2134/20394. 


\title{
Driver Sleepiness on YouTube: A Content Analysis
}

\author{
Hawkins, A. N., \& Filtness, A. J*.
}

Queensland University of Technology,

Centre for Accident Research and Road Safety - Queensland (CARRS-Q)

*Corresponding author: Ashleigh Filtness

Email: ashleigh.filtness@qut.edu.au

Fax: +61 (0) 731380111

Phone: $+61(0) 731387713$

Address: $\quad$ Centre for Accident Research \& Road Safety - Queensland

Queensland University of Technology

Kelvin Grove Campus

204 Level 2, K Block

130 Victoria Park Road QLD 4059 Australia 


\begin{abstract}
Driver sleepiness is a major contributor to severe crashes and fatalities on our roads. Many people continue to drive despite being aware of feeling tired. Prevention relies heavily on education campaigns as it is difficult to police driver sleepiness. Video sharing social media site YouTube is extremely popular, particularly with at risk driver demographics. Content and popularity of uploaded videos can provide insight into the quality of publicly accessible driver sleepiness information. The purpose of this research was to answer two questions; firstly, how prevalent are driver sleepiness videos on YouTube? And secondly, what are the general characteristics of driver sleepiness videos in terms of (a) outlook on driver sleepiness, (b) tone, (c) countermeasures to driver sleepiness, and, (d) driver demographics.
\end{abstract}

Using a keywords search, 442 relevant videos were found from a five year period (2nd December 2009 - 2nd December 2014). Tone, outlook, and countermeasure use were thematically coded. Driver demographic and video popularity data also was recorded. The majority of videos portrayed driver sleepiness as dangerous. However, videos that had an outlook towards driver sleepiness being amusing were viewed more often and had more mean per video comments and likes. Humorous videos regardless of outlook, were most popular. Most information regarding countermeasures to deal with driver sleepiness was accurate. Worryingly, $39.8 \%$ of videos with countermeasure information contained some kind of ineffective countermeasure. The use of humour to convey messages about the dangers of driver sleepiness may be a useful approach in educational interventions.

Keywords: driver behaviour, driver drowsiness, driver fatigue, driver tiredness, social media

\title{
Highlights
}

- 5 years of YouTube videos featuring driver sleepiness and fatigue were identified.

- Tone, outlook on fatigue and driver information for 442 YouTube videos was coded.

- Misinformation and trivialisation of dangers are present with high viewership.

- Most videos consider dangers of fatigue but fail to engage viewers when not humorous.

- YouTube is an effective platform for a humorous approach to convey safety messages. 


\section{Introduction}

Driver sleepiness (also referred to as driver-fatigue) related crashes account for $15-30 \%$ of vehicle crashes (Horne and Reyner 1995b, Akerstedt 2000, Connor et al. 2002, Williamson et al. 2011) and are associated with a higher risk of death and severe injury than other crashes (Horne and Reyner 1995b). Young drivers are most at risk (Pack et al. 1995, Blazejewski et al. 2012). The true prevalence of such crashes is widely acknowledged to be underestimated (Horne and Reyner 1995a, Liu et al. 2009). In part, underestimation occurs because sleepiness is difficult for the police to determine (Radun et al. 2013), but also because not all fatigue related crashes are reported to the police (Armstrong et al. 2013). Approximately $70 \%$ of drivers report driving when they are sleepy (Armstrong et al. 2013). Fatigued drivers are close to three times more likely to be involved in a crash or near-miss than non-fatigued drivers (Klauer et al. 2006). There is imperative need to address this prevalent and dangerous driving state.

Mitigating sleep-related crashes remains a challenge for road safety authorities. Any legal requirement not to drive when fatigued is difficult to enforce, as police officers have no accurate objective measure of fatigue. Therefore, strategies to reduce driver fatigue are heavily reliant on driver education and public awareness campaigns (Fletcher et al. 2005). It has been reported that drivers are generally aware of tiredness signs and how to most effectively counteract sleepiness (Anund et al. 2008). Despite this, self-reported prevalence of driving when sleepy is high (Sagaspe et al. 2010, Armstrong et al. 2013). This disparity suggests that although education may be effective at imparting information it is less effective at evoking response. It is unclear why this disparity exists, but driving when fatigued if the driver has an accurate knowledge of the risks may be considered as risk-taking behaviour. Risk-taking behaviour itself is known to be influenced by sleep loss, for example under total sleep deprivation participants are more likely to engage in risk if potential gains are considered (Mckenna et al., 2007). Similarly, adolescents who self-report low sleep quality are more likely to engage in risk-taking than individuals with good sleep quality (Telzer et al 2013). One 
factor which increases prevalence of risk-taking and irresponsible behaviour is glorification of such behaviour by the media (Fischer et al. 2011, Fischer et al. 2012).

The internet has grown in dominance as a source of media exposure in the developed world. As such, social media is becoming an increasingly common method for information dissemination (Akagi 2008). Free video sharing website YouTube is the third most visited website worldwide, with approximately 1 billion users (YouTube Statistics, 2015). Previous research of YouTube footage has documented that there is a vast amount of health information available (e.g. Keelan et al. 2007, Hussin et al. 2011, Lewis et al. 2011, Murugiah et al. 2011, Garg et al. 2015). However, there are limited investigations into road safety and driver behaviour footage (Steadman et al. 2014).

To our knowledge YouTube content has not been analysed in relation to driver sleepiness. YouTube was established in 2005, meaning those aged 16-17 who are currently obtaining learner driving permits, have grown up with access to this website. Most young adults in developed countries have regular internet access and they are likely to engage in video sharing more than any other age group (Lenhart 2009). As young drivers are most at risk of driver fatigue crashes, and online activities influence youth behaviour (Lewis et al. 2011) this is a topic which merits exploration.

The current study presents a content analysis of driver sleepiness videos on YouTube. The content and popularity of these videos provide insight into the quality of publicly accessible driver sleepiness information. This investigation is a first step towards understanding what content is available, how it is received and potentially, considerations for the design of future education strategies. As such, the following research questions will be addressed:

RQ1: How prevalent are driver sleepiness videos on YouTube?

RQ2: What are the general characteristics of driver sleepiness videos in terms of (a) outlook on driver sleepiness, (b) tone, (c) countermeasures to driver sleepiness, and (d) driver demographics? 


\section{Method}

\subsection{Data collection}

Using the inbuilt YouTube search function on 9th December 2014, a search of the last five years (2nd December 2009 - 2nd December 2014) was conducted using words related to driver sleepiness: "sleepy driving", "driving sleepy", "tired driver", "drowsy driver", "falling asleep while driving", "driver fatigue", "sleeping driver", "tired driving", "driving tired", "fatigue driving", "drowsy driving", "driving drowsy" and "sleepy driver". This approach was similar to that taken by Keelan et al (2007) who conducted a YouTube content analysis of all videos identified using the inbuilt search function for "vaccination" and "immunization". A Google Trends analysis confirmed each term had been searched sufficient times (in relation to all Google searches) to register with Google Trends, with "sleeping driver", "driver fatigue" and "drowsy driving" as most searched for. A very popular search term "asleep at the wheel" was excluded because the majority of results were related to a music band of that name.

\subsection{Data Analysis}

\subsubsection{Video coding}

The number of relevant videos identified allowed for all to be coded in a comprehensive analysis. This is in contrast to YouTube content analysis of other topics, where the coded sample is commonly limited to those with most views or on the first 10 pages (e.g. Garg et al., 2015; Hussin et al 2011). Each video was watched and the content independently coded by two researchers. Content was deductively considered under three predefined themes: (1) tone of the video, (2) outlook on driver sleepiness, (3) portrayal of driver sleepiness (including countermeasures and driver demographics). In instances of disagreement the two coders re-watched the video together and discussed until consensus was reached. Discussion included the tone of 166 (37.6\%) videos and the outlook on driver sleepiness of 118 (26.7\%) videos. For videos where consensus could not be reached independent coding was undertaken by a third researcher. A final decision was made when two of 
the three researchers agreed. The third researcher considered the tone of 15 (3.4\%) videos and outlook of $23(5.2 \%)$ videos.

The tone of each video was coded as 'humorous', 'neutral' or 'serious'. Videos were considered to be humorous if the subject was acting in a light hearted way or making a joke. Neutral videos did not include any cues to indicate an attitude and were predominantly raw accident footage. Serious videos delivered information in a sombre manner.

Outlook on driver tiredness was coded as either 'dangerous', 'amusing', 'does not impact driving' or 'can be overcome'. Outlook was distinct from tone, as some videos used humour to relate a message that driver sleepiness is dangerous. Outlook was considered to be 'dangerous' if negative consequences of driver sleepiness were shown or mentioned. 'Amusing' videos had a mocking or joking aspect and negative consequences of driver sleepiness featured were made fun of. An outlook of 'does not impact driving' was assigned to videos that did not feature or express concern for impairment or other negative consequences associated with driver sleepiness. Videos classified as 'can be overcome' focused on countermeasures to overcome sleepiness and were particularly confident that they made driving safe. This approach of coding using predefined categories has previously been demonstrated as an effective approach to YouTube footage content analysis on the topic of immunization (Keelan et al 2007).

Several aspects contributed to portrayal of driver sleepiness. Countermeasures were categorised as effective or ineffective at mitigating driver sleepiness. Effective countermeasures included: take a nap, get adequate sleep the night before driving, caffeine, schedule regular stops, swap drivers, pull over if tired, limit driving at times when you are usually asleep, avoid alcohol, get a lift/don't drive if tired, seek medical advice for sleep disorders, commercial drivers follow the hours of service laws, avoid medications with drowsy side effects, don't start a long trip if you are already tired and educate young drivers (Anund and Kecklund, 2011; Anund et al. 2008; Fletcher et al. 2005). Ineffective countermeasures included: stretch/adjust posture, talk to passengers, cold air, listen to 
loud music/audio book, yell/sing, drink water, eat/chew gum, wet face, slap yourself, don't use cruise control, hold your mobile out of the window, have a red interior light, record a video blog and pre-drive meditation (Anund and Kecklund, 2011; Anund et al. 2008; Reyner and Horne 1998). Videos which contained countermeasures were categorised by containing exclusively 'effective', exclusively 'ineffective' or 'mixed' information. Additionally, gender of the driver portrayed as experiencing driver sleepiness and the type of vehicle being driven were noted for each unique video.

\subsubsection{Reception}

The reception of the video was recorded as number of views, mean daily views (total views/number of days online), number of likes, number of dislikes, and number of comments received. Reception metrics are reported as total, mean and range. This approach to quantifying reception including mean daily views is similar to that of other YouTube content analyses (e.g. Murugiah et al 2011). The reception of the videos was compared by tone and outlook. Reception of videos including countermeasures was considered by tone. All duplications of the same video were considered together to get a complete picture of the reception. Finally, the content of the ten most viewed driver sleepiness videos are presented.

\subsection{Data analysis}

Frequency of each reception measure is presented cumulatively for the type of video, with mean and range. Where sample size allowed, Kruskal-Wallis Tests compared differences between tone and countermeasure effectiveness. Mann-Whitney post-hoc analyses with adjusted $p$ value were used to interpret findings.

\section{Results}

The initial search identified 559 videos. Videos were excluded from analysis if driver sleepiness was not shown, discussed or only very briefly mentioned. For example, children in toy cars and passengers falling asleep were excluded. Additionally some videos had to be excluded because they 
were taken down or had changed privacy settings shortly after the search was conducted. In total, 117 videos were excluded, leaving 442 relevant videos. Videos uploaded more than once were included in analysis but labelled as 'duplicate videos' and the earliest uploaded copy was considered the original video. In total there were 358 unique videos and 84 duplicate videos.

\subsection{Outlook on driver sleepiness}

The reception of videos based on their outlook on driver sleepiness is summarised in Table 1. By far the greatest proportion of videos presented an outlook of driver sleepiness as 'is dangerous'.

However, videos with an 'amusing' outlook received the greatest mean views per video, comments and likes. No statistical analysis was undertaken to compare reception between outlook types due to the disproportionate number of 'dangerous' outlook videos.

Table 1: Reception of videos by outlook on driver tiredness

\begin{tabular}{|c|c|c|c|c|c|}
\hline & & $\begin{array}{r}\text { Outlook is } \\
\text { dangerous }\end{array}$ & Is amusing ${ }^{2}$ & $\begin{array}{r}\text { Does not } \\
\text { impact } \\
\text { driving }^{3} \\
\end{array}$ & $\begin{array}{r}\text { Can be } \\
\text { overcome }\end{array}$ \\
\hline \multirow[t]{3}{*}{ \# views } & total & $1,642,321$ & 313,905 & 11,533 & 20,331 \\
\hline & mean per video & 4,116.09 & $18,465.00$ & 823.79 & $1,694.25$ \\
\hline & (range) & $(1-994,852)$ & $(1-289,297)$ & $(4-8,907)$ & $(1-9,718)$ \\
\hline \multirow[t]{2}{*}{ \# daily views } & mean per video & 17.43 & 17.41 & 0.75 & 3.61 \\
\hline & range & $(0.003-4146.21)$ & $(0.05-273.70)$ & $(0.01-5.66)$ & $(0.03-28.50)$ \\
\hline \multirow[t]{3}{*}{ \# likes } & total & 4,156 & 1,299 & 29 & 281 \\
\hline & mean per video & 10.42 & 76.41 & 2.07 & 23.42 \\
\hline & range & $(0-3,088)$ & $(0-1,240)$ & $(0-18)$ & $(0-106)$ \\
\hline \multirow[t]{3}{*}{ \# dislikes } & total & 656 & 28 & 14 & 42 \\
\hline & mean per video & 1.64 & 1.65 & 1.00 & 3.50 \\
\hline & range & $(0-355)$ & $(0-24)$ & $(0-14)$ & $(0-36)$ \\
\hline \multirow[t]{3}{*}{ \# comments } & total & 1,113 & 215 & 16 & 129 \\
\hline & mean per video & 2.79 & 12.65 & 1.14 & 3.50 \\
\hline & range & $(0-659)$ & $(0-181)$ & $(0-6)$ & $(0-58)$ \\
\hline
\end{tabular}

${ }^{1} 90.3 \%$ of all analysed videos $(n=399),{ }^{2} 3.8 \%$ of all analysed videos $(n=17),{ }^{3} 3.3 \%$ of all analysed videos $(n=14),{ }^{4} 2.7 \%$ of all analysed videos $(n=12)$

\subsection{Video tone}

Table 2 presents reception by tone. There was a significant difference in number of views, daily views, likes and dislikes between tones. Videos that were 'humorous' in tone had significantly more 
views than 'neutral' videos $(p=.008)$. There was no difference in the number of views between 'humorous' and 'serious' videos ( $p=.056)$ or' neutral' and 'serious' $(p=.531)$. 'Humorous' videos received significantly more daily views than 'neutral' tone videos $(p=.001)$.

'Humorous' videos were also more effective at engaging the audience as they received significantly more likes than 'neutral' ( $p<.001)$ and 'serious' $(p<.001)$ videos, and received significantly more dislikes than 'neutral' $(p=.004)$ but not 'serious' $(p=.784)$ videos. 'Neutral' videos received significantly more dislikes than 'serious' videos $(p=.001)$.

Table 2: Reception of videos by tone

\begin{tabular}{|c|c|c|c|c|c|c|}
\hline & & Humorous $^{1}$ & Neutral $^{2}$ & Serious $^{3}$ & $\chi^{2}(d f)$ & $p$ \\
\hline \multirow{3}{*}{ \# views } & total & $1,339,420$ & 499,663 & 149,007 & \multirow{3}{*}{$\begin{array}{r}6.827 \\
(2)\end{array}$} & \multirow[t]{3}{*}{.033} \\
\hline & mean per video & $25,758.08$ & $4,129.45$ & 553.93 & & \\
\hline & (range) & $(1-994,852)$ & $(1-194,872)$ & $(1-23,640)$ & & \\
\hline \multirow[b]{2}{*}{ \# daily views } & mean per video & 45.60 & 37.92 & 1.28 & \multirow{2}{*}{$\begin{array}{r}13.136 \\
(2)\end{array}$} & \multirow[t]{2}{*}{.001} \\
\hline & (range) & $(0.02-1,924.28)$ & $(0.003-4,146.21)$ & $(0.003-101.90)$ & & \\
\hline \multirow[t]{5}{*}{ \# likes } & total & 2,204 & 3,529 & 337 & \multirow{3}{*}{$\begin{array}{r}25.883 \\
(2)\end{array}$} & \multirow[t]{3}{*}{$<.001$} \\
\hline & mean per video & 42.38 & 29.17 & 1.25 & & \\
\hline & (range) & $(0-1,240)$ & $(0-3,088)$ & $(0-61)$ & & \\
\hline & total & 199 & 487 & 54 & \multirow{3}{*}{$\begin{array}{r}13.043 \\
(2)\end{array}$} & \multirow[t]{3}{*}{.001} \\
\hline & mean per video & 3.83 & 4.02 & 0.20 & & \\
\hline \multirow[t]{3}{*}{ \# dislikes } & (range) & $(0-165)$ & $(0-355)$ & $(0-36)$ & & \\
\hline & total & 353 & 1,164 & 328 & \multirow{3}{*}{$\begin{array}{r}5.252 \\
(2)\end{array}$} & \multirow[t]{3}{*}{.072} \\
\hline & mean per video & 6.79 & 9.62 & 1.22 & & \\
\hline \# comments & (range) & $(0-181)$ & $(0-659)$ & $(0-21)$ & & \\
\hline
\end{tabular}

${ }^{1} 11.8 \%$ of all analysed videos $(n=52),{ }^{2} 27.4 \%$ of all analysed videos $(n=121),{ }^{3} 60.9 \%$ of all analysed videos $(n=269)$

\subsection{Countermeasures}

$46 \%(n=165)$ of the unique videos featured or mentioned countermeasures for driver sleepiness. In order to understand the potential for misinformation, Table 3 summarises these countermeasures.

Twenty four videos recommended a driver alert system as a countermeasure to driver tiredness. The effectiveness of each individual alert system is unknown and therefore these videos were excluded from the countermeasures analysis. 
As can be seen in Table 3 exclusively effective countermeasure information was most frequently communicated in a 'serious' manner. Almost equal in exposure however, were videos with a mixture of effective and ineffective countermeasures. 'Humorous' videos with 'mixed' countermeasure information were the average most viewed per video. No statistical analysis was undertaken to compare reception between countermeasure effectiveness or to compare reception of countermeasures between tones due to the disproportionate number of videos.

Table 3: Countermeasure type by tone of video, mean views per day and mean views per video

\begin{tabular}{llrrr}
\hline & & Effective & Ineffective & $\begin{array}{r}\text { Mixture of effective } \\
\text { and ineffective }\end{array}$ \\
\hline \multirow{5}{*}{ Humorous } & total views & $6245^{\mathrm{a}}$ & $2471^{\mathrm{b}}$ & $10660^{\mathrm{c}}$ \\
& mean views per video & 567.73 & 494.20 & 1776.67 \\
& (range) & $(10-2,459)$ & $(11-1,768)$ & $(43-6,060)$ \\
& mean views per day & 0.76 & 0.79 & 3.53 \\
& (range) & $(0.02-3.30)$ & $(0.03-2.30)$ & $(0.21-11.93)$ \\
\hline \multirow{5}{*}{ Serious } & total views & $745^{\mathrm{d}}$ & $91^{\mathrm{e}}$ & $17789^{f}$ \\
& mean views per video & 667.87 & 45.50 & 658.85 \\
& (range) & $(1-12,405)$ & $(5-86)$ & $(8-9,461)$ \\
& mean views per day & 1.40 & 0.17 & 0.88 \\
& (range) & $(0.02-28.50)$ & $(0.16-0.17)$ & $(0.03-10.08)$ \\
\hline \multirow{5}{*}{ Neutral } & total views & $1771^{\mathrm{g}}$ & $31^{\mathrm{h}}$ & $1250^{\mathrm{i}}$ \\
& mean views per video & 442.75 & 31.00 & 625.00 \\
& (range) & $(41-1,411)$ & - & $(1-1249)$ \\
& mean views per day & 0.34 & 0.03 & 0.52 \\
\hline \multirow{5}{*}{ Total } & (range) & $(0.07-0.98)$ & - & $(0.03-1.01)$ \\
\hline & number of videos & $99(70.2 \%)$ & $7(5.0 \%)$ & $35(34.8 \%)$ \\
& total views & 8761 & 2593 & 29699 \\
& mean views per video & 88.49 & 370.43 & 848.52 \\
& mean views per day & 1.31 & 0.61 & 1.31 \\
\hline
\end{tabular}

a $7.8 \%$ of all analysed videos $(n=11),{ }^{b} 3.8 \%$ of all analysed videos $(n=4),{ }^{c} 4.3 \%$ of all analysed videos $(n=6),{ }^{d} 59.6 \%$ of all analysed videos $(n=84),{ }^{e} 1.4 \%$ of all analysed videos $(n=2),{ }^{f} 19.1 \%$ of all analysed videos $(n=27),{ }^{g} 59.6 \%$ of all analysed videos $(n=84),{ }^{h} 0.7 \%$ of all analysed videos $(n=$ $1),{ }^{i} 1.4 \%$ of all analysed videos $(n=2)$

\subsection{Driver portrayal}

Cars were the most common vehicle featured in unique videos $(n=229 ; 64.0 \%)$ followed by commercial trucks ( $n=34 ; 9.5 \%)$. Busses, trains and other forms of transport featured less often ( $n=$ 
$13 ; 3.6 \%)$. When identifiable, male drivers ( $n=155 ; 43.3 \%$ ) appeared in more unique videos than female drivers ( $n=59 ; 16.5 \%)$.

\subsection{Most viewed}

The URLs of the ten most viewed videos are provided as an appendix. The most viewed videos were as follows:

1. By far the most viewed video, an animated Korean Government safety advertisement featuring popular television characters (total views =994852), outlook 'is dangerous', 'humorous' tone, 2 duplicates.

2. Amateur footage of a driver pretending to fall asleep to scare passengers (total views =289297), Outlook 'amusing', 'humorous' tone.

3. Dash-cam footage of a head on collision between two passenger cars and a following vehicle (total views $=194872$ ), outlook 'is dangerous', 'neutral' tone, 6 duplicates.

4. Dash-cam footage of a near miss with an oncoming truck (total views $=102603$ ), outlook 'is dangerous', 'neutral' tone, 2 duplicates.

5. Dash-cam footage of a near miss, passenger car entering the lane of a motorbike (total views =98236), outlook 'is dangerous', 'neutral' tone.

6. Dash-cam footage of a crash between a police car and passenger car (total views $=41943$ ), outlook 'is dangerous', 'neutral' tone, 11 duplicates.

7. Australian Government commercial, a stylised car crash (total views $=23640$ ), outlook 'is dangerous', 'serious' tone, 3 duplicates.

8. Amateur footage of a young woman struggling to stay awake while driving, while the passenger laughs (total views $=14822$ ), outlook 'amusing', 'humorous' tone.

9. Car manufacturer's advertisement promoting inbuilt driver alert systems (total views $=12405$ ), outlook 'is dangerous', 'serious' tone, 3 duplicates.

10. Professionally produced short clip offering 'quick tips' (total views $=9718)$. Outlook 'can be overcome', 'serious' tone. 


\section{Discussion}

Driver sleepiness is extremely dangerous as tired drivers are three times more likely to have a crash or near-miss than alert drivers (Klauer et al. 2006). An inherent difficulty with sleepiness detection for enforcement purposes necessitates a reliance on drivers to manage and take action against their own sleepiness. The glorification of risk taking by the media increases prevalence of risky behaviour (Fischer et al. 2011, Fischer et al. 2012), therefore, it is important to understand how the high risk behaviour of driver sleepiness is being portrayed. YouTube was the focus of the current work because young adults are the most susceptible group to driver sleepiness (Horne and Reyner 1995b, Connor et al. 2002, Filtness et al. 2012) and are most likely to engage in online video sharing (Lenhart A 2009). Driver sleepiness related videos are frequently posted on YouTube. Encouragingly the majority of these videos portrayed a message that driver tiredness is dangerous. Hopefully this goes some way to encouraging viewers not to drive when they are sleepy. However, although the majority of videos are clear in their outlook that this behaviour is dangerous, their influence may be limited, as each individual video gained fewer views on average than videos that trivialized driver sleepiness as being 'amusing'. Furthermore, when 'amusing' outlook videos are considered in combination with the other equally concerning categories of 'can be overcome' and 'does not impact driving' this relatively small number of videos gain far more views on average than the plentiful 'dangerous' outlook videos. These categories also attract more likes and comments per video indicating a higher level of audience engagement with the material.

Comments provide a point of interaction within the online community. Videos that claimed tiredness 'can be overcome' may attract comments because they are open to, or even asking for, discussion. These videos' contentious claims could be encouraging if the comments involve disputing misinformation. Generating this kind of discussion could be advantageous in making driver sleepiness a topic that viewers feel personally involved with. There is evidence to suggest that commenters often read and respond to other online comments and discussion can become 
impassioned and strongly divided views emerge, particularly on raw dash-cam footage of crashes (Hawkins and Filtness, 2015) .

Road safety campaigns have traditionally employed a serious tone in advertisements. In recent years this approach has been challenged as the benefits of a humours tone are being recognised (Lewis et al. 2007). The potential benefit for using humour is supported by the current finding that regardless of the outlook on driver sleepiness, videos receive greater viewership if they have a humorous tone. It is possible that humour would be an effective way to spread a driver sleepiness safety message. Videos that were humorous in tone gained more views and likes. On average they also attracted more comments than serious videos. This is consistent with YouTube being used largely as a source of entertainment.

Of those videos where countermeasures were shown or mentioned, the majority featured exclusively effective countermeasures. This reflects previous research which has demonstrated that drivers are generally aware of what countermeasures are effective (Anund et al. 2008). However, several videos contained ineffective countermeasures. These included listening to music which has been shown to worsen the situation by distracting the driver from how sleepy they really are (Reyner and Horne 1998). Additionally, some ineffective countermeasures (e.g holding mobile out of window, filming a video blog) presented their own road safety hazard by distracting the driver. This is particularly concerning as tired drivers are more susceptible to distraction and exhibit further impaired driving performance (Anderson and Horne 2006). The vast majority of videos featured passenger cars and male drivers, which is encouraging as it reflects those most commonly involved in sleep crashes (Connor et al. 2002).

The most watched driver sleepiness video was a 'humorous' toned, Korean road safety advertisement. This is a clear example that YouTube can be effectively used to disseminate road safety information (Steadman et al. 2014). Two of the ten most viewed videos included 'amusing' footage of someone falling asleep while driving. One of these was obviously staged, however the 
eighth most viewed video appeared to be footage taken by a passenger of their driver struggling to stay awake. This is an extreme trivialisation of driver sleepiness as the passenger does not appear to realise that they are in a dangerous situation. Rather than asking the driver to pull over, they choose to film what potentially could have resulted in a crash. Future research may wish to consider passenger attitude towards driver sleepiness; to date this is largely under investigated.

A limitation of the current analysis is that it does not consider how videos are perceived by viewers. Notably, raw crash footage from an in-vehicle dash-cam was classified as 'dangerous' in outlook, however many of these videos were uploaded by entertainment themed channels and therefore may have been intended to be perceived as 'funny' or 'humorous'. User comments on this type of YouTube video often express finding them funny or a distorted perception of who is at fault (Hawkins and Filtness, 2015). Further research should consider examining how views' perception of dash-cam footage can effect receptivity to safety messages. This is particularly important as four of the ten most viewed videos were dash-cam footage. It is not meaningful to consider what proportion of YouTube videos are about driver sleepiness because of the huge number of videos listed on YouTube, and the nature of sites use, whereby users search for videos of interest to view rather than viewing all content. However, to provide some context, the number of videos identified in the current work is lower than that of similar content analysis for "distracted driving" which identified 1000 videos (Steadman et al 2014), but, there were more driver sleepiness videos than the 153 identified videos in a search for "vaccination" and "immunization" (Keelan et al 2007). From the current analysis it is not possible to determine the impact that watching these videos has on viewer's intentions and actual driver sleepiness behaviour. Future research may wish to consider quantifying viewer's response to this type of video, for example considering if driving behaviour changes following viewing.

YouTube and other social networking platforms allow researchers to tangibly observe what has captured the public's interest (e.g. (Mclver et al. 2015)). Views can help spread effective or 
ineffective messages depending on what the video uploader chooses to share. Comments, likes and dislikes can indicate that the public are engaging with driver-sleepiness footage. Road safety and public health authorities should consider YouTube and humorous content in particular as a potentially useful dissemination point of educational and interventional material.

\section{Acknowledgements}

The authors are grateful to Ms Gelareh Eighani for assisting with the video coding. 


\section{Appendix}

Ten most viewed driver fatigue videos

1. "[LARVA Public Campaign] Drowsy driving [HD]"

https://www.youtube.com/watch?v=c3dy7c3lpew

2. "Sleepy Driver No. 1" https://www.youtube.com/watch?v=jo0yaPNLAQg

3. "Sleeping Driver Causes Extremely Bad 3 Car Crash on rt 21 fayette county" https://www.youtube.com/watch?v=iWwzOTOyAfA

4. "Luckiest Sleeping Driver Ever" https://www.youtube.com/watch?v=Vv4TZ5eaEgc

5. "Biker Wakes up sleeping driver" https://www.youtube.com/watch?v=RIYicl8VuDk

6. "Dashcam Video Shows Cop Car Taken Out By Sleepy Driver"

https://www.youtube.com/watch?v=Mz8NuxWtoD0

7. "Drowsy Driving - you can't fight sleep - TAC ad"

https://www.youtube.com/watch?v=J6keUM1ATmg

8. “Hilarious girl falling asleep while driving" https://www.youtube.com/watch?v=9DAEQGiuRXw

9. "The New ŠKODA Octavia: Driver Fatigue Sensor"

https://www.youtube.com/watch?v=fh5b7Bgq5_U

10. "Quick Tips: How to Combat Driver Fatigue" https://www.youtube.com/watch?v=wstDNXpE80k

\section{References}

Akagi, C., 2008. Youtube? For health education? American Journal of Health Education 39 (1), 58-60. Akerstedt, T., 2000. Consensus statement: Fatigue and accidents in transport operations. Journal of Sleep Research, 9(4), 395-395.

Anderson, C., Horne, J., 2006. Sleepiness enhances distraction during a monotonous task. Sleep, 29 (4), 573-576.

Anund, A., \& Kecklund, G. (2011). Sleepiness, crases and the effectiveness of countermeasures: Swedish National Road and Transport Reasearch Institute. From: www.divaportal.se/smash/get/diva2:669238/FULLTEXT01.pdf

Anund, A., Kecklund, G., Peters, B., Åkerstedt, T., 2008. Driver sleepiness and individual differences in preferences for countermeasures. Journal of Sleep Research, 17(1), 16-22.

Armstrong, K., Filtness, A.J., Watling, C.N., Barraclough, P., Haworth, N., 2013. Efficacy of proxy definitions for identification of fatigue/sleep-related crashes: An australian evaluation. Transportation Research Part F: Traffic Psychology and Behaviour, 21, 242-252.

Blazejewski, S., Girodet, P.-O., Orriols, L., Capelli, A., Moore, N., Group, C., 2012. Factors associated with serious traffic crashes: A prospective study in southwest france. Archives of Internal Medicine, 172(13), 1039-1041. 
Connor, J., Norton, R., Ameratunga, S., Robinson, E., Civil, I., Dunn, R., Bailey, J., Jackson, R., 2002. Driver sleepiness and risk of serious injury to car occupants: Population based case control study. BMJ, 324(7346), 1125.

Filtness, A.J., Reyner, L.A., Horne, J.A., 2012. Driver sleepiness-comparisons between young and older men during a monotonous afternoon simulated drive. Biological Psychology, 89(3), 580-583.

Fischer, P., Greitemeyer, T., Kastenmüller, A., Vogrincic, C., Sauer, A., 2011. The effects of riskglorifying media exposure on risk-positive cognitions, emotions, and behaviors: A metaanalytic review. Psychological Bulletin, 137(3), 367-390.

Fischer, P., Krueger, J.I., Greitemeyer, T., Asal, K., Aydin, N., Vingilis, E., 2012. Psychological effects of risk glorification in the media: Towards an integrative view. European Review of Social Psychology, 23(1), 224-257.

Fletcher, A., Mcculloch, K., Baulk, S.D., Dawson, D., 2005. Countermeasures to driver fatigue: A review of public awareness campaigns and legal approaches. Australian and New Zealand Journal of Public Health, 29(5), 471-476.

Garg, N., Venkatraman, A., Pandey, A., Kumar, N., 2015. Youtube as a source of information on dialysis: A content analysis. Nephrology, 20(5), 315-320.

Hawkins, A., \& Filtness, A. J. (2015 October). In-vehicle filming of driver fatigue on YouTube: vlogs, crashes and bad advice. Accepted paper to be presented at Australasian Road Safety Conference. Gold Coast, Australia.

Horne, J., Reyner, L., 1995a. Driver sleepiness. Journal of Sleep Research, 4 (s2), 23-29.

Horne, J., Reyner, L., 1995b. Sleep related vehicle accidents. BMJ, 310 (6979), 565-567.

Hussin, M., Frazier, S., Thompson, J.K., 2011. Fat stigmatization on youtube: A content analysis. Body Image, 8(1), 90-92.

Keelan, J., Pavri-Garcia, V., Tomlinson, G., Wilson, K., 2007. Youtube as a source of information on immunization: A content analysis. JAMA, 298 (21), 2482-2484.

Klauer, S.G., Dingus, T.A., Neale, V.L., Sudweeks, J., Ramsey, 2006. The impact of driver inattention on near-crash/crash risk: an analysis using the 100-car Naturalistic Driving Study Data DOT HS 810594.

Lenhart A, 2009. Teens and Social Media: An Overview. Washington, DC: Pew Internet and American Life; Retrieved 09 June 2015, from: http://www.pewinternet.org/2015/04/09/teens-socialmedia-technology-2015/

Lewis, I.M., Watson, B., White, K.M., Tay, R., 2007. Promoting public health messages: Should we move beyond fear-evoking appeals in road safety? Qualitative Health Research, 17(1), 61-74.

Lewis, S.P., Heath, N.L., St Denis, J.M., Noble, R., 2011. The scope of nonsuicidal self-injury on youtube. Pediatrics, 127 (3), 552-557.

Liu, C.C., Hosking, S.G., Lenné, M.G., 2009. Predicting driver drowsiness using vehicle measures: Recent insights and future challenges. Journal of Safety Research, 40(4), 239-245.

Mciver, D.J., Hawkins, J.B., Chunara, R., Chatterjee, A.K., Bhandari, A., Fitzgerald, T.P., Jain, S.H., Brownstein, J.S., 2015. Characterizing sleep issues using twitter. Journal of medical Internet research, 17(6), 140.

Mckenna, B. S., Dickinson, D. L., Orff, H. J., \& Drummond, S. (2007). The effects of one night of sleep deprivation on known-risk and ambiguous-risk decisions. Journal of Sleep Research, 16(3), 245-252.

Murugiah, K., Vallakati, A., Rajput, K., Sood, A., Challa, N.R., 2011. Youtube as a source of information on cardiopulmonary resuscitation. Resuscitation, 82(3), 332-334.

Pack, A.I., Pack, A.M., Rodgman, E., Cucchiara, A., Dinges, D.F., Schwab, C.W., 1995. Characteristics of crashes attributed to the driver having fallen asleep. Accident Analysis \& Prevention, 27(6), 769-775. 
Radun, I., Ohisalo, J., Radun, J., Wahde, M., Kecklund, G., 2013. Driver fatigue and the law from the perspective of police officers and prosecutors. Transportation research part F: traffic psychology and behaviour, 18, 159-167.

Reyner, L., Horne, J., 1998. Evaluation of'in-car'countermeasures to sleepiness: Cold air and radio. Sleep, 21(1), 46-51.

Sagaspe, P., Taillard, J., Bayon, V., Lagarde, E., Moore, N., Boussuge, J., Chaumet, G., Bioulac, B., Philip, P., 2010. Sleepiness, near-misses and driving accidents among a representative population of french drivers. Journal of Sleep Research, 19(4), 578-584.

Telzer, E. H., Fuligni, A. J., Lieberman, M. D., \& Galván, A. (2013). The effects of poor quality sleep on brain function and risk taking in adolescence. Neuroimage, 71, 275-283.

YouTube Statistics - YouTube. Retrieved 09 June 2015, from: https://www.youtube.com/yt/press/statistics.html.

Steadman, M., Chao, M.S., Strong, J.T., Maxwell, M., West, J.H., 2014. Cu I8ter: Youtube distracted driving PSAs use of behavior change theory. American Journal of Health Behavior, 38(1), 312.

Williamson, A., Lombardi, D.A., Folkard, S., Stutts, J., Courtney, T.K., Connor, J.L., 2011. The link between fatigue and safety. Accident Analysis \& Prevention, 43(2), 498-515. 